\title{
An Experimental Study of Confinement of Circular RCC Columns using Mild Steel Rings (March 2016)
}

\author{
Sachin Bhadouria ${ }^{1}$, Dharmendra Raghuwanshi ${ }^{2}$, Pankaj Kumar Patel ${ }^{3}$, Vinod Kumar Patel ${ }^{4}$, \\ Ramnayan Patel $^{5}$, Chaitanya Mishra ${ }^{6}$, Dr A. N. Patel ${ }^{7}$ \\ ${ }^{6,7}$ Guide
}

\begin{abstract}
The research investigates the advantages of using confinement to improve the axial compression load carrying capacity of RCC cylinders using mild steel rings. For this, confinement by Mild steel rings have been done to RCC cylinders to mimic real structural columns which may otherwise have to be discarded due to poor strength performance. The experimental programme included compression load testing a number of RCC cylindrical specimen to establish the effect the confinement had on the compressive load-carrying capacity. Effect of grade of concrete was also investigated in the study.It was found that confinement of RCC Columns increase axial load bearing capacity. The confinement yielded an increase in axial load bearing capacity of Circular RCC Columns by Confinement of Mild Steel Rings is 43.20 $\%$ for Fe415 grade of Steel and M25 grade of concrete.The confinement yielded an increase in axial load bearing capacity of Circular RCC Columns by Confinement of Mild Steel Rings is $40.74 \%$ of Fe415 grade of Steel and M20 grade of concrete.
\end{abstract}

Keywords: M20, M25 Grade of concrete, Fe415,Fe250 Grade of steel, M.S. Rings

\section{Introduction}

The Rehabilitation of existing reinforced concrete columns may be required for a number of reasons. Many older buildings require rehabilitation and structural strengthening to allow for continued service if a change in the use or occupancy is planned or to improve the load Carrying capacity caused by deficient concrete as evidenced by low cube strength results. In the case of the latter, the structural column may need to be removed and re-placed leading to Significant financial costs and time implications. Therefore, the most practical solution to lesser the risk of structural collapse is by external strengthening. Significant advances in the understanding of structural behavior have occurred over the past 40 years. However, the lack of strict design criteria for older and deficient concrete elements has made them particularly susceptible to failure. A common detailing problem found in older reinforced concrete columns is widely spaced transverse ties or links. This leads to poor confinement and support to longitudinal reinforcement required to delay the strength degradation of concrete under ultimate load conditions and allow a ductile response. Failure of a column can be catastrophic and may cause partial or even complete structural collapse.

\section{Proposed Idea}

Continuous confinement has always increased the load carrying capacity of columns, as already known from literature. As we think of reducing the cost of confinement, continuous confinement proves to be more uneconomical. To address the cost issue, the intermittent confinement can be a Solution to the problem, if it found technically suitable.

\section{Need}

Continuous confinement has always increased the load carrying capacity of columns, as already known from literature. As we think of reducing the cost of confinement, continuous confinement proves to be more uneconomical. To address the cost issue, the intermittent confinement can be a solution to the problem, if it found technically suitable. Therefore the thought encouraged us to develop the hypothesis in this direction. Retrofitting of structure is necessary to increase its life. In rural houses to increase its design load, retrofitting is one of the important techniques. Confinement is technique of rehabilitation of structure \& by confining it through M.S. Steel tubes increases its load carrying capacity of column but from economical point of view intermittent confinement is more economical than continuous confinement so it is our hypothesis that intermittent confinement through mild steel rings increases failure load of structure. "The intermittent confinement of cylindrical RCC columns using mild steel rings will increase axial load bearing capacity".

\section{Experimental Results}

The experimental work \& Results -

Table 1: Results of M25 Grade of concrete \& Fe- 415 Grade of steel

\begin{tabular}{|c|c|c|c|}
\hline S. No. & Specimen & $\begin{array}{c}\text { Failure Load for M25 \& } \\
\text { Fe-415 in KN ( Circular } \\
\text { RCC Columns) }\end{array}$ & $\begin{array}{c}\text { Failure Load for M25 \& } \\
\text { Fe-415 KN Confined } \\
\text { Circular RCC Columns }\end{array}$ \\
\hline 1 & 1 & 566.9 & 1000 \\
\hline 2 & 2 & 538.4 & 995.4 \\
\hline 3 & 3 & 566 & 949.7 \\
\hline Avg. & & 557.1 & 981.7 \\
\hline
\end{tabular}




\section{International Journal of Science and Research (IJSR) \\ ISSN (Online): 2319-7064 \\ Index Copernicus Value (2013): 6.14 | Impact Factor (2015): 6.391}

Table 2: Results of M20 Grade of concrete \& Fe-415 Grade of steel-

\begin{tabular}{|c|c|c|c|}
\hline $\begin{array}{c}\text { S. } \\
\text { No. }\end{array}$ & Specimen & $\begin{array}{c}\text { Failure Load for M20 \& } \\
\text { Fe-415 in KN ( Circular } \\
\text { RCC Columns) }\end{array}$ & $\begin{array}{c}\text { Failure Load for M20 \& Fe- } \\
\text { 415 KN Confined Circular } \\
\text { RCC Columns }\end{array}$ \\
\hline 1 & 1 & 548.38 & 882.81 \\
\hline 2 & 2 & 486.12 & 802 \\
\hline 3 & 3 & 510.42 & 927.52 \\
\hline Avg. & & 514.97 & 870.78 \\
\hline
\end{tabular}

\section{Conclusion}

It is concluded that, the increase in failure load is compared in table given below,

Table 3: Grade of Concrete M25

\begin{tabular}{|c|c|c|}
\hline S. No. & $\begin{array}{c}\text { Failure Load without } \\
\text { Confinement (in KN) }\end{array}$ & $\begin{array}{c}\text { Failure Load with } \\
\text { confinement (in KN) }\end{array}$ \\
\hline 1 & 566.9 & 1000 \\
\hline 2 & 538.4 & 995.4 \\
\hline 3 & 566 & 949.7 \\
\hline Avg. & $\mathbf{5 5 7 . 1}$ & $\mathbf{9 8 1 . 7}$ \\
\hline
\end{tabular}

From our experimental work, the overall increase in the failure load by using confinement of mild steel rings is given below for Fe415 Steel, M25 Grade of Concrete-

Table 4: Grade of Concrete M25

\begin{tabular}{|c|c|c|}
\hline S. No. & $\begin{array}{c}\text { Difference in failure load } \\
\text { of with confinement \& } \\
\text { without confinement (KN) }\end{array}$ & $\begin{array}{c}\text { Percentage increase in } \\
\text { failure load by } \\
\text { confinement (KN) }\end{array}$ \\
\hline 1 & $1000-566.9=431.10$ & $43.31 \%$ \\
\hline 2 & $995.4-538.4=457$ & $45.91 \%$ \\
\hline 3 & $949.7-566=383.7$ & $40.40 \%$ \\
\hline Avg. & $\mathbf{4 2 3 . 9 3}$ & $\mathbf{4 3 . 2 0} \%$ \\
\hline
\end{tabular}

Table 5: Grade of Concrete M20

\begin{tabular}{|c|c|c|}
\hline S. No. & $\begin{array}{c}\text { Failure Load without } \\
\text { Confinement (in KN) }\end{array}$ & $\begin{array}{c}\text { Failure Load with } \\
\text { confinement (in KN) }\end{array}$ \\
\hline 1 & 548.38 & 882.81 \\
\hline 2 & 486.12 & 802 \\
\hline 3 & 510.42 & 927.52 \\
\hline Avg. & $\mathbf{5 1 4 . 9 7}$ & $\mathbf{8 7 0 . 7 8}$ \\
\hline
\end{tabular}

Table 6: Grade of Concrete M20

\begin{tabular}{|c|c|c|}
\hline S. No. & $\begin{array}{c}\text { Difference in failure load of } \\
\text { with confinement }\end{array}$ & $\begin{array}{c}\text { Percentage increase in } \\
\text { failure load by confinement }\end{array}$ \\
\hline 1 & $882.81-548.38=343.43$ & $37.88 \%$ \\
\hline 2 & $802-486.12=315.88$ & $39.37 \%$ \\
\hline 3 & $927.52-510.42=417.10$ & $44.97 \%$ \\
\hline Avg. & $\mathbf{7 6 1 . 6 3}-\mathbf{5 6 8 . 7 6}=\mathbf{1 9 3 . 8 7}$ & $\mathbf{4 0 . 7 4 \%}$ \\
\hline
\end{tabular}

From our experimental work, the overall increase in the failure load by using confinement of mild steel rings is given below for Fe415 Steel, M20Grade of Concrete-

So, it can be concluded on the basis of Experimental Work-
- The increment in failure load is $\mathbf{4 3 . 2 0} \%$ of Confined Circular RCC Column of Fe415 Grade of Steel \&M25 Grade of Concrete.

- The increment in failure load is $\mathbf{4 0 . 7 4} \%$ of Confined Circular RCC Column of Fe415 Grade of Steel \&M20 Grade of Concrete

\section{Future Work}

On the basis of our experimental work, rehabilitation of structure can be carried by confinement of Circular RCC Columns to increase load carrying capacity through mild steel rings. In our experimental work, we have calculated the axial load carrying capacity of circular RCC Columns and their crack patterns by using M25 \& M20 grade of concrete. We can extend our work of confinement by increasing thickness of mild steel rings and similarly in the case of uni-axial and biaxial loading of columns, their load carrying capacity can be improved by Confinement.

\section{References}

[1] Kwan, A., Dong, C., and Ho, J. (2016). "Axial and lateral stress-strain model for circular concrete-filled steel tubes with external steel confinement." Engineering Structures, 10.1016/j.engstruct.2016.03.026,528-541. Online publication date: 1-June 2016.

[2] Lu, Y., Liang, H., Li, S., and Li, N. (2015). "Axial behaviour of RC columns strengthened with SCC filled square steel tubes." Steel and Composite Structures, 10.12989/scs.2015.18.3.623， 623-639. Online publication date: 25-Mar-2015.

[3] Shih, C., Chu, S., Liou, Y., Hsiao, F., Huang, C., Chiou, T., and Chiou, Y. (2014). "In Situ Test of School Buildings Retrofitted with External Steel-Framing Systems." Journal of Structural Engineering, 10.1061/(ASCE)ST.1943-541X.0001063, D4014002. Online publication date: 1-Jan-2015.

[4] Sezen, H. and Miller, E. (2010). "Experimental Evaluation of Axial Behaviour of Strengthened Circular ReinforcedConcrete Columns." Journal of Bridge Engineering, 10.1061/(ASCE)BE.1943-5592.0000143, 238-247.Online publication date: 1-Mar-2011.

[5] Xiao, Y., He, W., and Choi, K. (2005). "Confined Concrete-Filled Tubular Columns." Journal of Structural Engineering, 10.1061/(ASCE)07339445(2005)131:3(488), 488-497. Online publication date: 1-Mar-2005.

[6] Xiao, Y. and Wu, H. (2003). "Retrofit of Reinforced Concrete Columns Using Partially Stiffened Steel Jackets." J. Struct. Eng., 10.1061/(ASCE)07339445(2003)129:6(725), 725-732.

[7] Indian standard 10262 for design mix of concrete. 